\title{
INTERROGATIVE UTTERANCES WITH THE PARTICLE LI (NE LI) IN THE LITERARY TEXT
}

\author{
Jiang Wei \\ Far Eastern Federal University, Vladivostok, Russia
}

\begin{abstract}
This paper aims at analyzing interrogative utterances with the particle li (ne li) in the literary text, the features of which are manifested in syntactic, functional-semantic, pragmatic and stylistic aspects. Functionalsemantic types of interrogative utterances are singled out, and syntactic and pragmatic functions of interrogative utterances with the particle $l i$ are analyzed. In addition, a comparative analysis of their use in works of different genres (drama, prose) and various authors (M. Bulgakov, M. Gorky) is conducted. Differences between the use of the particle $l i$ in drama and prose are insignificant and are manifested in monologic speech in prose works of both authors. In the works by M. Bulgakov, ne-li-questions are often complicated by the particle $u z h$. In M. Bulgakov's prose, special question-answer constructions are noted. In M. Bulgakov's prose there are also interrogative utterances with the particle $l i$ that are addressed to readers in order to catch their attention. M. Gorky's prose is characterized by the syntactic formulation of questions: complex all-union sentences with different types of relations. In the drama and prose by M. Gorky, author's use of punctuation marks is noted. The author's dash in the texts of M. Gorky's works is mainly used in two situations: 1) in such syntactic conditions, where this sign is not regulated; 2) when there is the need of strengthening the position of the punctuation mark.

Key words: particle $l i$, combination $n e l i$, function of questions, primary functions of questions, secondary functions of questions, hybrid functions of questions, literary text, stylistic aspect.

Citation. Jiang Wei. Interrogative Utterances with the Particle $L i(\mathrm{Ne} \mathrm{Li}$ ) in the Literary Text. Vestnik Volgogradskogo gosudarstvennogo universiteta. Seriya 2, Yazykoznanie [Science Journal of Volgograd State University. Linguistics], 2018, vol. 17, no. 3, pp. 174-180. (in Russian). DOI: https://doi.org/10.15688/jvolsu2.2018.3.18

\section{ВОПРОСИТЕЛЬНЫЕ ВЫСКАЗЫВАНИЯ С ЧАСТИЦЕЙ ЛИ (НЕ ЛИ) В ХУДОЖЕСТВЕННОМ ТЕКСТЕ}

\author{
Цзян Вэй \\ Дальневосточный федеральный университет, г. Владивосток, Россия
}

\begin{abstract}
Аннотация. Статья посвящена вопросительным высказываниям с частицей ли (не ли) в художественном тексте, особенности которых проявляются в синтаксическом, функционально-семантическом, прагматическом и стилистическом аспектах. Выделены функционально-семантические типы вопросительных высказываний и проанализированы синтаксические и прагматические функции вопросительных высказываний с частицей ли. Проведен сравнительный анализ их употребления в пьесах, романах, повестях, рассказах М. Булгакова, М. Горького. Различия в употреблении частицы ли в произведениях, относящихся к разным родам литературы, незначительны и проявляются в монологической речи у обоих авторов. В произведениях М. Булгакова наблюдаются: частотное осложнение частицей уж в не ли-вопросах; особые вопросно-ответные построения; вопросы, которые обращены к читателю с целью активизировать его 올 внимание. В прозе М. Горького вопросы имеют типичное синтаксическое оформление: бессоюзные сложные предложения определенных типов. В произведениях М. Горького отмечено авторское употребление э. знаков препинания: авторское тире ставится чаще всего в двух случаях - в таких синтаксических условиях, () где этот знак не регламентирован, и для усиления позиции знака препинания.
\end{abstract}


Ключевые слова: частица ли, сочетание не ли, функции вопросов, первичные функции вопроса, вторичные функции вопроса, гибридные функции вопроса, художественный текст, стилистика.

Цитирование. Цзян Вэй. Вопросительные высказывания с частицей ли (не ли) в художественном тексте // Вестник Волгоградского государственного университета. Серия 2, Языкознание. - 2018. - Т. 17, № 3. C. 174-180.-DOI: https://doi.org/10.15688/jvolsu2.2018.3.18

\section{Введение}

Частицы настолько значимы в процессе общения, что лишенная их речь воспринимается как излишне сухая, невежливая, ибо в ней нет контакта, связи, отношения, даже взаимопонимания [Николаева, 1985, с. 13]. Они принадлежат к традиционным объектам лингвистических исследований. Это закономерно, поскольку частицы - это класс функциональный, «это слова, для которых коммуникативно-прагматическая функция является единственной или основной» [Стародумова, 2002, c. 260]. Каждая из таких единиц нуждается в специальном изучении, позволяющем выявить своеобразие их значений и функций.

Функции частиц системно представлены в работах Е.А. Стародумовой. Исследователь выделяет коммуникативно-прагматические, коммуникативно-синтаксические, текстовые, конструирующие и стилистические функции [Стародумова, 1997]. Наименее изучены частицы в стилистическом аспекте, хотя их употребление в разных стилях рассматривалось многими лингвистами. Прежде всего частицы изучались в основной сфере своего бытования в разговорной речи. Фундаментальным исследованием в этом отношении является монография Н.Ю. Шведовой «Очерки по синтаксису русской разговорной речи» [Шведова, 1960]. Наиболее подробное описание функционирования частиц в художественном тексте содержится в монографии Е.А. Иванчиковой, где проведено наблюдение над частицами в прозе Ф.М. Достоевского в связи с особенностями синтаксической композиции художественного текста [Иванчикова, 1979]. Использование отдельных частиц в художественном тексте рассматривается и в ряде других исследований (см., например: [Бирюкова, 2007; Гурьева, 1991; Токарчук, 2010]).

В центре нашего внимания находятся вопросительные высказывания с частицей ли, не раз становившиеся объектом изучения в лингвистике. Учеными выделены типы воп- росов с точки зрения синтаксиса, семантики, прагматики [Баранов, Кобозева, 1983; Дастамуз, 2013; Распопов, 1955; Шатуновский, 2008]. При этом специальных стилистических исследований ли-вопросов до сих пор не проводилось.

Материалом для нашей работы послужили вопросительные высказывания с частицей ли, функционирующие в драматических и прозаических произведениях М. Булгакова и М. Горького. Всего проанализировано около 800 употреблений частицы ли в 37 драматических и 21 прозаическом произведениях. Фактический материал рассматривался как единый массив фактов, его систематизация проведена с учетом дифференциации функций вопросительных предложений, представленной в «Русской грамматике» [Русская грамматика, 1980, т. 2, с. 393-396].

\section{Характеристики ли-вопросов, общие для произведений \\ М. Булгакова и М. Горького}

Вопросительные высказывания имеют первичные (получение ответа) и вторичные (непосредственное сообщение о чем-либо) функции [Русская грамматика, 1980, т. 2, с. 394]. В первичных функциях частица ли оформляет вопросительное высказывание в целом (общевопросительная функция) либо выделяет то слово, которое называет предмет вопроса (частновопросительная функция). При этом чаще данная частица используется в общевопросительных высказываниях.

Ли-вопросы допускают утвердительный и отрицательный ответы, но в ответах могут находиться новые сведения о чем-либо, имеющие характер уточнения или объяснения ответа-подтверждения или ответа-отрицания, например:

(1) - Знаешь ли какой-либо язык, кроме арамейского?

- Знаю. Греческий (Булгаков, т. 9, с. 170). 


\section{МАТЕРИАЛЫ И СООБЩЕНИЯ}

Не ли-вопросы отличаются тем, что в них выражается предположительное значение:

(2) Прокурор. Не шпион ли Чичиков? Не старается ли он что-нибудь разведать? (Булгаков, т. 6 , c. 137).

В произведениях М. Булгакова и М. Горького представлены две разновидности ли-вопросов с первичными функциями:

- нейтральный вопрос:

(3) - Знаешь ли грамоту?

- Да (Булгаков, т. 9, с. 170),

- вопрос, осложненный эмоциональными оттенками:

(4) Геккерен. Грудь, грудь цела ли? (Булгаков, т. 7, c. 287).

Частица ли в примере (4) подчеркивает озабоченность, тревогу говорящего.

Употребление частицы ли тесно связано с прагматическим намерением говорящего. В вопросительных высказываниях с первичными функциями распространены такие типичные выражения, как верно ли, правда ли, точно ли, так ли. Их целью является желание проверить достоверность сообщаемого:

(5) Николай I. Верно ли, что Геккерен нашептывал Пушкиной?

Дубельт. Верно, ваше величество (Булгаков, т. 7, c. 280$)$.

В исследуемом материале зафиксирована особая разновидность вопроса - «отгаданный» вопрос:

(6) Анна. Я хочу спросить вас и не могу... вы знаете, о чем я хочу спросить вас?..

Лидия. Да. Пожалуй, знаю... Люблю ли я вашего мужа, - это? Нет (Горький, т. 6, с. 440).

В вопросительном высказывании посредством указательного местоимения это говорящий проверяет, правильно ли он понял собеседника, угадывает его вопрос и отвечает на него.

Среди ли-вопросов во вторичных функциях преобладают риторические вопросы, вопросы-побуждения и вопросы, которые имеют целью активизировать внимание.

В анализируемых текстах зафиксированы риторические вопросы и вопросы с модальными словами.
Риторические вопросы представлены двумя типичными их разновидностями:

- вопросы с фразеологизированной структурой:

(7) Дон Кихот. Вам ли это спрашивать, бакалавр? Для меня это долг чести! (Булгаков, т. 8, с. 276),

- вопросы с модальными словами мочь, можно, нужно, сто́ит и подобными:

(8) Ольга Алексеевна. Могу ли я быть спокойной, Варя? Он приехал из города, заглянул на минутку домой и исчез... (Горький, т. 6, с. 214).

Частица ли может оформлять вопрос, побуждающий к совершению или прекращению действия:

(9) Чарнота (Кричит с галереи). Перестанешь ли ты, турецкая морда, мне душу надрывать? (Булгаков, т. 5, с. 276).

В данном случае частица подчеркивает требование прекращения действия собеседника, показывает, что говорящий потерял всякое терпение.

Частица ли оформляет вопросы, которые имеют целью активизировать внимание. Для привлечения внимания адресата используются выражения видишь ли, знаешь ли и т. п., которые содержат адресатную форму глагола - второе лицо:

(10) - Знаете ли вы, семь чертей и одна ведьма вам в зубы, что чиновник, которому вы жаловались, теперь женится на моей дочери?

- Виноваты, Антон Антонович! (Булгаков, т. 7, c. 194).

Другой способ привлечения внимания использование вопросно-ответной конструкции:

(11) Дон Кихот. Люди выбирают разные пути. ...Иду ли я по одной из этих дорог? Нет! Я иду по крутой дороге рыцарства и презираю земные блага, но не честь! (Булгаков, т. 5, с. 280).

Существуют вопросы-побуждения с гибридными функциями, например, вопросительные высказывания с не ли, которые выражают просьбу говорящего. Такие высказывания можно квалифицировать по-разному, поскольку они совмещают первичную (ожидание ответа) и вторичную (просьба) функции: 
(12) Леди. Не потрудитесь ли вы объяснить мне, что означала эта маленькая мизансцена, которую я застала? (Булгаков, т. 5, с. 186).

\section{Характеристики ли-вопросов, различающие произведения М. Булгакова и М. Горького}

В произведениях М. Булгакова в не ли-вопpocax часто наблюдается осложнение частицей уж, которая показывает, что описываемая ситуация выходит за границы представления говорящего о возможном, и употребляется обычно для выражения неожиданности ситуации с точки зрения говорящего:

(13) Сольский. Не видно в двух шагах. Выходит, дело плоховато... Уж не забыли ль нас? (Булгаков, т. 7, с. 378$)$.

В прозе М. Булгакова частица ли употребляется в особых вопросно-ответных построениях: говорящий задает вопрос и сам на него отвечает, чтобы обратить внимание условного, неконкретного собеседника:

(14) Уж не пожар ли это в Старом Лувре? Нет, это тысячи свечей горят в люстрах Гвардейского зала, и в свете их оживают неподвижные кариатиды (Булгаков, т. 6, с. 363).

Вопрос с комплексом частиц уж, не ли применяется автором для наглядного представления ситуации.

В прозе М. Булгакова частица ли используется также в вопросе, который обращен к читателю с целью активизировать его внимание.

(15) Приходилось ли вам когда-либо читать пьесу один на один кому-нибудь? Это очень трудная вещь, уверяю вас (Булгаков, т. 8, с. 142).

В произведениях М. Булгакова вопросительные высказывания с ли и не ли главным образом являются простыми предложениями, среди которых наблюдаются и вопросы, образованные от невопросительных предложений, и вопросы, построенные по собственным синтаксическим образцам (инфинитивные предложения, предложения фразеологизированной структуры). Кроме того, ли-вопросы (не ли-вопросы) в некоторых случаях входят в состав сложного бессоюзного предложения.
Таким образом, у М. Булгакова синтаксис вопросов «классический», каких-либо отклонений не наблюдается.

Специфика употребления частицы ли в произведениях М. Горького ярко проявляется в синтаксическом и пунктуационном оформлении высказывания.

Частотно синтаксическое оформление вопросительных высказываний - бессоюзные сложные предложения определенных типов: предложения с незамещенной синтаксической позицией в двух разновидностях - изъяснительные и предложения с опосредованным изъяснением. Отмечены также предложения с пояснением, со значением причины и следствия. Приведем примеры:

- бессоюзные предложения с изъяснительным значением:

(16) Приходилось думать сразу о многом, и нужно было сейчас же решить: так ли он поступил, как следовало? (Горький, т. 16, с. 531);

- бессоюзные предложения с опосредованными изъяснительными отношениями (термин Е.Н. Ширяева [Ширяев, 1984]). В нашем материале обнаруживаются предложения с вопросительной частью, имеющие семантическую особенность - наличие отношений цели (в вопросе выражена цель действия субъекта):

(17) Бабушка присела отдохнуть, а я зашел за деревья - нет ли еще гриба? (Горький, т. 13, с. 247).

Вопросительная часть примера (17) передает следующий смысл: «Зашел за деревья, чтобы посмотреть, нет ли еще гриба». Частица ли вносит оттенок заинтересованности.

- Вопросительные бессоюзные высказывания со значением причины и следствия:

(18) - А конечно!.. Не ты наживал - тебе ли жалеть? (Горький, т. 4, с. 185);

- Вопросительные бессоюзные предложения с пояснительными отношениями:

(19) - И вот ныне я предлагаю тебе даже на выбор два послушания: хочешь ли ты в конторе сидеть, или - в келейники к отцу Антонию? (Горький, т. 8, с. 285).

Значение словосочетания два послушания поясняется вопросом с частицей ли, которая 


\section{МАТЕРИАЛЫ И СООБЩЕНИЯ}

выполняет в данном контексте и союзную функцию: ли - или выражает альтернативу.

Обращает на себя внимание использование вопросительных бессоюзных высказываний в романе «Жизнь Клима Самгина». В произведении такие предложения с частицей ли имеют свою специфику: в большинстве случаев они представлены как рефлексивные вопросы, которые являются основным синтаксическим способом передачи состояния героя. В романе вопрос такого типа в основном используется как форма выражения внутренней неуверенности, например:

(20) Клим долго, напряженно искал в себе: являлось ли у него сожаление, о котором догадывается Лидия? (Горький, т. 19, с. 175).

(21) Когда рабочий ушел, он несколько минут стоял среди комнаты, сунув руки в карманы, решая: следует ли идти к Варваре? (Горький, т. 20, с. 99).

(22) В продолжение минуты он честно поискал: нет ли в прошлом чего-то, что Варвара могла бы поставить в вину ему? (Горький, т. 21, с. 168).

Выделенные слова в вопросах отражают колебание говорящего, что соответствует значению частицы ли.

Особенности пунктуации в предложениях с частицей ли в текстах произведений М. Горького заключаются в наличии авторского тире, которое в основном ставится в двух случаях: в таких синтаксических условиях, где этот знак не регламентирован; для усиления позиции знака препинания.

В первом случае тире ставится, в частности, между главными членами предложения:

(23) Федосья. Сонюшка, Андрюша-то Рязанов - жив ли? (Горький, т. 12, с. 16).

Как считает Н.С. Валгина, авторское тире в такой позиции обозначает актуальное членение [Валгина, 2004, с. 191].

Не регламентированное правилами тире может также появиться после союзов, частиц, наречных слов [Шапиро, 1955, с. 338]. В нашем материале такие случаи зафиксированы. Например:

(24) Софья. О! Я хочу спасти вашего сына... Может быть, это научит меня помочь моим детям... Но - могу ли я? Сумею ли? (Горький, т. 12, с. 38).
С одной стороны, говорящий хочет спасти сына собеседника, с другой стороны, говорящий затрудняется это сделать. Тире усиливает такое противопоставление. Последовательное употребление частицы ли подчеркивает затруднение и неуверенность спрашивающего.

Во втором случае авторская индивидуальность проявляется в усилении позиции знака препинания, когда тире вытесняет запятую для повышения экспрессивности вопроса. Например:

(25) - Подкидыш ты народный! Понимаешь ли - о ком говоришь? Вот вы все так, гордионы, дармоеды и грабители земли, не знаете, на кого лаете, паршивые псы! (Горький, т. 8, с. 333).

Авторского употребления знаков препинания в произведениях М. Булгакова не отмечено.

\section{Выводы}

1) Исследование демонстрирует многофункциональность вопросительных высказываний с частицей ли. Вопросы имеют различное синтаксическое оформление и обнаруживают отнесенность к разным функционально-семантическим типам. Прагматические возможности вопросных конструкций реализуются при употреблении их в конкретной речевой ситуации.

2) Вопросительные высказывания с частицей ли (не ли) могут выполнять первичные, вторичные, а также гибридные функции (совмещение первичной и вторичной функций).

3) Частица ли обладает большими возможностями использования: уточнение смысла вопроса, усиление различных прагматических значений, участие в формировании конструкций особого синтаксического типа и др.

\section{СПИСОК ЛИТЕРАТУРЫ}

Баранов А. Н., Кобозева И. М., 1983. Семантика общих вопросов в русском языке (категория установки) // Известия АН СССР. Серия литературы и языка. Т. 42, № 3. С. 263-274.

Бирюкова О. А., 2007. Семантико-прагматические функции и стилистические возможности частиц в художественном тексте (на материале прозы С. Довлатова) : дис. ... канд. филол. наук. Владивосток. 207 c. 
Валгина Н. С., 2004. Актуальные проблемы современной русской пунктуации. М. : Высшая школа. 259 с.

Гурьева Н. Н., 1991. Текстовые функции частицы вот (на материале «Сказок» М.Е. СалтыковаЩедрина) // Актуальные проблемы филологии в вузе и школе : Материалы 4-й Тверской межвуз. конференции молодых ученых-филологов и школьных учителей. Тверь : Тверской государственный университет. С. 62-64.

Дастамуз С., 2013. Коммуникативные свойства инфинитивных вопросительных предложений с частицей ли // Вестник Московского университета. Серия 9. Филология. № 2. С. 142-148.

Иванчикова Е. А., 1979. Синтаксис художественной прозы Достоевского. М. : Наука. 287 с.

Николаева Н. М., 1985. Функции частиц в высказывании. М. : Наука. 167 с.

Распопов И. П., 1955. К вопросу о частицах в современном русском языке (частица ли) // Русский язык в школе. № 6. С. 17-19.

Русская грамматика, 1980. Русская грамматика / под ред. Н. Ю. Шведовой. М. :Наука. Т. 2.710 с.

Стародумова Е. А., 1997. Русские частицы. Владивосток : Изд-во Дальневост. ун-та. 68 с.

Стародумова Е. А., 2002. Частицы русского языка: разноаспектное описание. Владивосток : Изд-во Дальневост. ун-та. 291 с.

Токарчук И. Н., 2010. Функционирование частиц в художественном тексте (К вопросу о стилистическом приеме и идиостиле) // Мир русского слова. № 4. С. 66-71.

Шапиро А. Б., 1955. Основы русской пунктуации. М. : Изд-во Академии Наук СССР. 398 с.

Шатуновский И. Б., 2008. Общие (полные) вопросы в русском языке // Динамические модели: слово, предложение, текст. М. : Изд-во ЯСК. С. 896-927.

Шведова Н. Ю., 1960. Очерки по синтаксису русской разговорной речи. М. : Изд-во Академии наук СССР. 377 с.

Ширяев Е. Н., 1984. Основы системного описания бессоюзных сложных предложений // Вопросы языкознания. № 1. С. 55-66.

\section{ИСТОЧНИКИ}

Булгаков - Собрание сочинений : в 10 т. М. : Голос, 1995-2000.

Горький - Полное собрание сочинений : в 30 т. М. : ГОСЛИТИЗДАТ, 1949-1955.

\section{REFERENCES}

Baranov A.N., Kobozeva I.M., 1983. Semantics of general questions in the Russian language (the category of attitude). Izvestiya AN SSSR.
Seriya literatury i yazyka, vol. 42, no. 3, pp. 263-274.

Biryukova O.A., 2007. Semantic and pragmatic functions and stylistic functions of particles in the literary text (based on the prose by S. Dovlatov). Cand. philol. sci. diss. Vladivostok. 207 p.

Valgina N.S., 2004. Pressing problems of modern Russian punctuation. Moscow, Vysshaya shkola Publ. 259 p.

Guryeva N.N., 1991. Text functions of the particle vot (based on the material of The Fairy Tales by M.E. SaltykovShchedrin). Aktualnye problemy filologii v vuze $i$ shkole: Materialy 4-y Tverskoy mezhvuz. konferentsii molodykh uchenykh-filologov $i$ shkolnykh uchiteley. Tver, Izd-vo TGU, pp. 62-64.

Dastamuz S., 2013. Communicative attributes of infinitive interrogative sentences with the particle li. Vestnik Moskovskogo universiteta. Seriya 9, Filologiya [Moscow State University Bulletin. Philology], no. 2, pp. 142-148.

Ivanchikova E.A., 1979. Syntax of Dostoevsky's artistic prose. Moscow, Nauka Publ. 287 p.

Nikolaeva T.M., 1985. Functions of particles in the utterance. Moscow, Nauka Publ. 167 p.

Raspopov I.P., 1955. On the problem of particles in modern Russian (particle li). Russkiy yazyk v shkole [Russian Language at School], no. 6, pp. 17-19.

Shvedova N.Yu., ed., 1980. Russian grammar. Moscow, Nauka Publ., vol. 2. 710 p.

Starodumova E.A., 1997. Russian particles. Vladivostok, Izd-vo Dalnevost. un-ta. $68 \mathrm{p}$.

Starodumova E.A., 2002. Particles of the Russian language: a multidimensional description. Vladivostok, Izd-vo Dalnevost. un-ta. 291 p.

Tokarchuk I.N., 2010. Functioning of particles in the literary text (on the issue of stylistic device and idiostyle). Mir russkogo slova [The World of Russian Word], no. 4, pp. 66-71.

Shapiro A.B., 1955. Basics of Russian punctuation. Moscow, Izd-vo Akademii Nauk SSSR. 398 p.

ShatunovskiyI.B., 2008. General (full) questions in Russian. Dinamicheskie modeli: slovo, predlozhenie, tekst, Moscow, YASK Publ., pp. 896-927.

Shvedova N.Yu., 1960. Essays on the syntax of Russian colloquial speech. Moscow, Izd-vo Akademii Nauk SSSR. 377 p.

Shiryaev E.N., 1984. Basics of systematic description of conjunctionless complex sentences. Voprosy yazykoznaniya [Topics in the Study of Language], no. 1, pp. 55-66.

\section{SOURCES}

Bulgakov M.A. Collected works. In 10 vols. Moscow, Golos Publ., 1995-2000.

Gorky M. Complete works. In 30 vols. Moscow, GOSLITIZDAT Publ., 1949-1955. 


\section{МАТЕРИАЛЫ И СООБЩЕНИЯ}

\section{Information about the Author}

Jiang Wei, Postgraduate Student, Department of Russian Language and Literature, Far Eastern Federal University, OPS Russkiy-2, 690922 Vladivostok, Russia, tszyan.vei@yandex.ru, https://orcid.org/ 0000-0003-4334-1203

\section{Информация об авторе}

Цзян Вэй, аспирант кафедры русского языка и литературы, Дальневосточный федеральный университет, ОПС Русский-2, 690922 г. Владивосток, Россия, tszyan.vei@yandex.ru, https:// orcid.org/0000-0003-4334-1203 